\title{
Prediction of Stresses and Settlement for TBM Tunnel Surrounding Soil
}

\author{
Waad A. Zakaria, Qasim A. Mahdi, Halah Hashim Muhammed \\ Department of civil Engineering, College of Engineering, University of Diyala \\ halahashim90@yahoo.com.
}

\begin{abstract}
In recent years, modern technology in the construction of tunnels using tunnel-boring machines (TBM) is implemented in the practice of civil engineering in large cities which significantly reduces the harmful effects of tunneling on the ground's surface. Construction of the tunnel becomes fundamental and the exploitation of underground space form part of the infrastructure to treat the growing problem of mass rapid transit in urban cities. The method of tunnel construction numerical modeling based on the finite element method is used to evaluate of the ground movement induce tunneling which is an essential matter to predict the settlement through construction and their effects on adjacent buildings. A method of surface settlement prediction is based on field data and results of construction phases

numerical modeling. In this study, the prediction of the settlement caused by tunneling by simulation model using numerical method (FEM), with Mohr-Coulomb. This method involves determination of the following characteristics of displacement process: the distribution of displacements, the position of the point of the maximum settlement and the value of the maximum settlement, and strains in the trough. The developed method for calculation of the settlements and he behavior of stress a round tunnel calculates and analysis the settlement during tunnel construction and compared with natural soil through various stages of construction of the tunnel. The results show the behavior of stresses of the native soil and predication of surface settlement through stages of construction of tunnel using the tunnel boring machines(TBM).
\end{abstract}

Keywords: TBM Tunnel, Surface Settlement, FEM Model.

Paper History: (Received:17-12-2018 ; Accepted:14-22019)

\section{Experimental Work \\ 3D-FEM Model}

The purpose of the numerical mechanized tunneling model is to take into consideration the large number of operations that take place through tunnel excavation and construction. The 3D finite element model consists of different components like as the soil parameters, soil layers, the tunneling machine, the

\section{Introduction}

Construction of tunneling requires a proper estimate of the magnitude and distribution of ground displacements due to tunneling is critical for the safety of adjacent structures. In an urban environment, the construction of tunnels causes ground movement during the excavation process. [1].

In recent years the excavation methods in soft soil have improved after tunnels have become economically more attractive in the urban environment. For example, the tunnel boring machine (TBM) has been widely utilized in tunnel construction, where the most purpose is to reduce the surface settlement of soil [2].

The construction methods have an important influence on the ground surface settlements, therefore the amount of ground surface settlement may differ according to different construction methods used for different crosssections of the tunnel which leads to different settlements [3]. The tunnel boring machine is methodical for the excavation of tunnels with a cross-section of circular and rectangular shape through the different types of soil strata.

In order to accurate prediction the distribution stresses and surface settlement during construction tunnel by finite element method (FEM) analysis has become popular tool which can simulate staged construction procedures for various types of soil and structure behavior by using constitutive models [4,5].

Many previous researchers have studied the patterns of settlement and distribution stresses by using one of the following approaches, analytical solutions, Empirical formulas, Numerical solutions and Physical modeling approach. In this paper, it is planned to use numerical modelling to predict the behavior of stresses surrounding soil tunnel, through excavation stages and application of lining segment of the tunnel design

hydraulic jacks, the application of tunnel lining and the tail void grout. All these parameters are analyzed and simulated in the 3D FEM model.

\section{Model Dimensions and soil Parameters}

The available FEM is used to simulate the construction of the tunnel. Due to the symmetry of the model, only half of the tunnel model is taken for 
calculations by the numerical solution. The diameter of the tunnel (D) is assumed to be equal to $8.5 \mathrm{~m}$ and for the longs is assumed $9 \mathrm{~m}$. The geometry and mesh discretization for the tunnel is shown in Figure-1, it is assumed that the crown of the tunnel sited at the depth of $1 \mathrm{D}$.

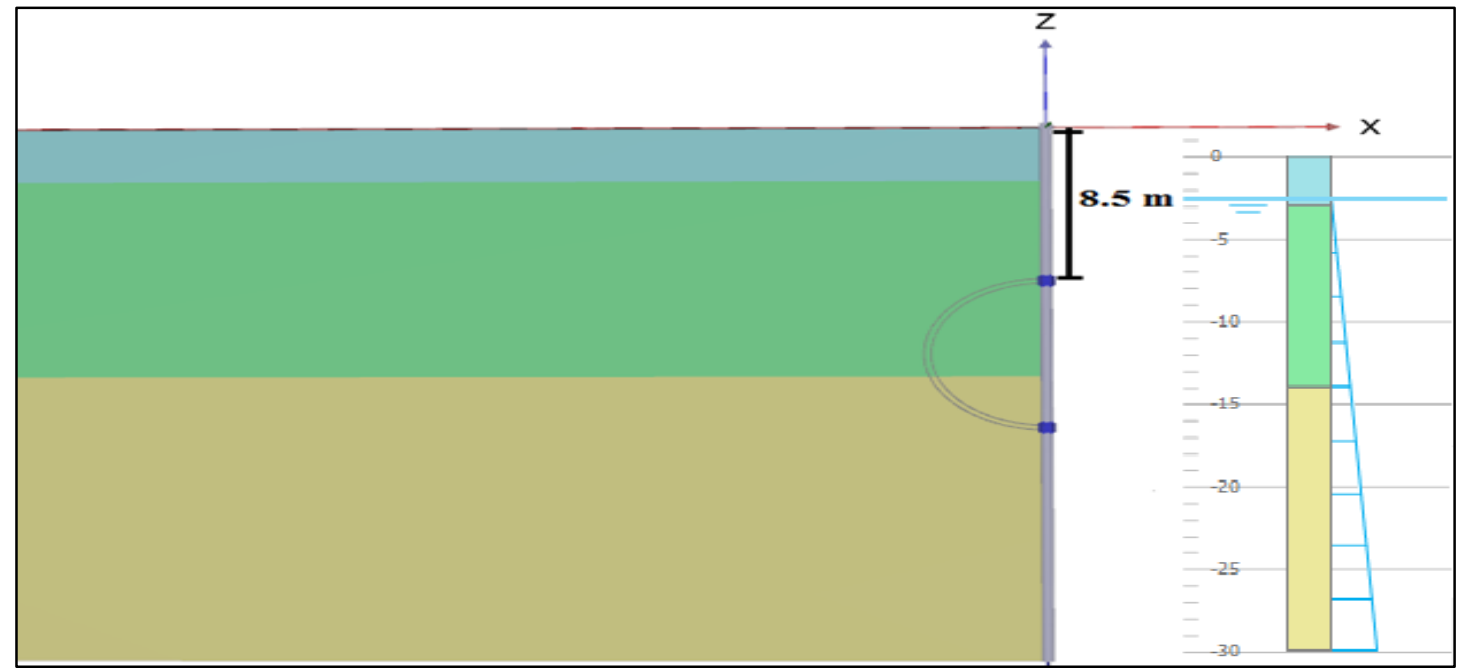

Figure 1: The geometry of the tunnel for the 3D model

The tunnel model is based on the actual data of soil properties in Diyala government, Figure 2 shows the soil layers at this zone. The parameters which be obtained from basic tests on soil borehole of the project and some parameters which are adopted form Blowles (1996) [10].
The Table1 can be shown the obtain data from field and laboratory tests of the project. The model used to behavior of soil in this study is Mohr-Coulomb model (MC).

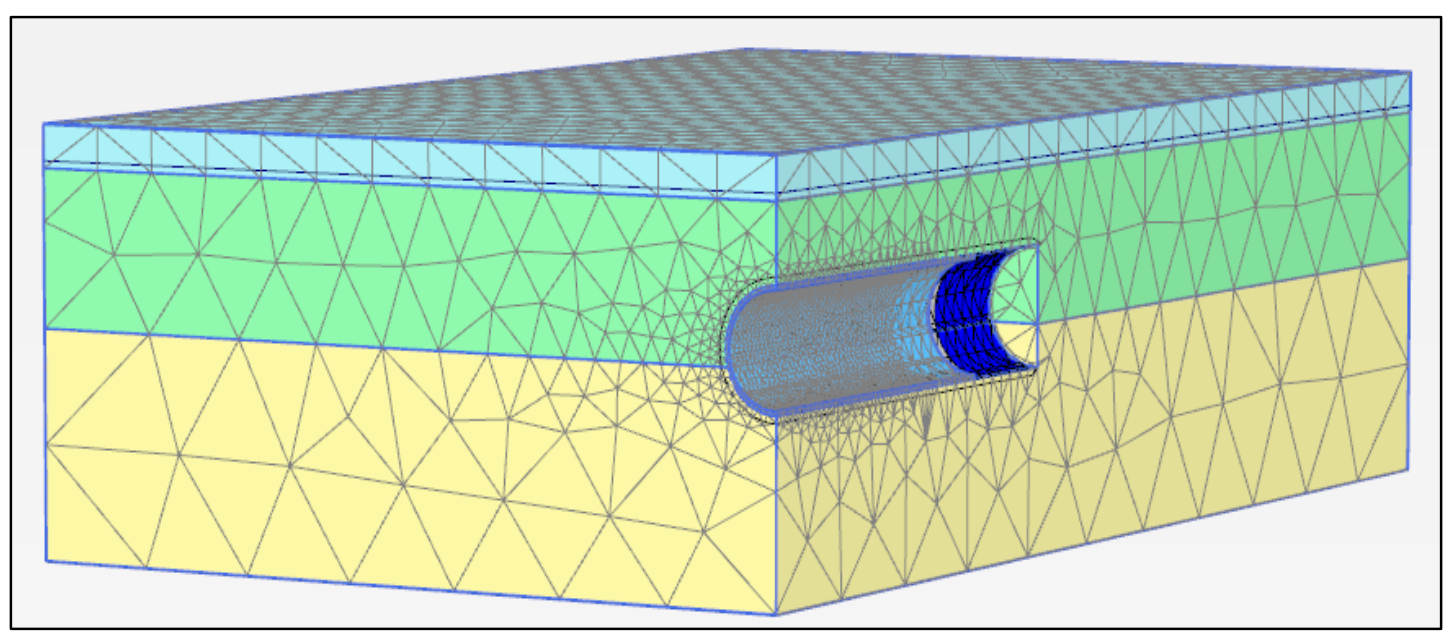

Figure 2: Coarser type mesh of 3D geometrical of the tunnel for (MC) model.

Table1: The soil parameters of Mohr-Coulomb model (MC)

\begin{tabular}{|c|c|c|c|c|c|c|c|}
\hline \multicolumn{2}{|c|}{ Depth (m) } & $\begin{array}{c}\text { Saturation } \\
\text { unite weight of } \\
\text { soil }\left(\mathrm{kN} \backslash \mathrm{m}^{3}\right)\end{array}$ & $\begin{array}{c}\text { Unsaturation } \\
\text { unite weight of } \\
\text { soil }\left(\mathrm{kN} \backslash \mathrm{m}^{3}\right)\end{array}$ & $\begin{array}{c}\text { Young's } \\
\text { modulus } \\
\times 10^{3} * \\
\left(\mathrm{kN} \backslash \mathrm{m}^{2}\right)\end{array}$ & $\begin{array}{c}\text { Cohesion } \\
\left(\mathrm{kN} \backslash \mathrm{m}^{2}\right)\end{array}$ & $\begin{array}{c}\text { Friction } \\
\text { angle } \\
\text { Degree } \\
(\mathrm{o})\end{array}$ & $\begin{array}{c}\text { Poisson's } \\
\text { Ratio }\end{array}$ \\
\hline Form & To & & & & & & \\
\hline $0-$ & 3 & 20.00 & 16.75 & 50 & 38 & & 0.3 \\
\hline $3-$ & 15 & 20.00 & 16.75 & 50 & 150 & & 0.3 \\
\hline $15-$ & 30 & 18.5 & 14.75 & 80 & 1 & 34 & 0.25 \\
\hline
\end{tabular}

* (Bowles 1996) 


\subsection{Structural Elements Properties}

In the model the TBM (tunnel boring machine) is modeled as plate elements and assumed as $9 \mathrm{~m}$ long. The segmental tunnel lining is also modeled as plate elements. Table 2 shows the parameters of the shield TBM machine [11]. The width of each concrete lining segment is assumed to be equal to $1.5 \mathrm{~m}$. Thus, TBM advances $1.5 \mathrm{~m}$ each step of the staged excavation. The concrete lining segments are modeled by using structural elements which behavior is obeyed isotropic linear elastic constitutive. The material properties of lining elements are shown in the Table 3.

Table2: Material of properties of the TBM [8].

\begin{tabular}{|c|c|c|}
\hline Parameter & Unite & TBM \\
\hline Thickness & Meter & 0.35 \\
\hline Elastic Modulus & $\left(\mathrm{Kn} \backslash \mathrm{m}^{2}\right)$ & $23.0^{*} 10^{6}$ \\
\hline Unit Weight & $\left(\mathrm{Kn} \backslash \mathrm{m}^{3}\right)$ & 120 \\
\hline Poisson's Ratio & - & 0.0 \\
\hline
\end{tabular}

Table-3. The material properties of the concrete lining element.

\begin{tabular}{|c|c|c|c|}
\hline Parameter & Unite & Lining & TBM \\
\hline Thickness & Meter & 0.25 & 0.35 \\
\hline Elastic Modulus & $\left({\left.\mathrm{Kn} \backslash \mathrm{m}^{2}\right)}_{23.5 * 10^{6}}\right.$ & $23.0^{*} 10^{6}$ \\
\hline Unit Weight & $\left(\mathrm{Kn} \backslash \mathrm{m}^{3}\right)$ & 24 & 120 \\
\hline Poisson's Ratio & - & 0.1500 & 0.0 \\
\hline
\end{tabular}

In this research the magnitude of face pressure is delimited with respect to the vertical stress originated from the weight of soil deposit, and its associated to the unit weight of bentonite suspension whereas the magnitude of grouting pressure is known via increasing the face pressure at the crown of the tunnel. The grouting pressure linearly increases from tunnel crown to invert as face pressure based on the unit weight of the grout material.

The first six excavation steps represent the advancement of $9 \mathrm{~m}$ at long TBM, the shell elements are activated with the assigned TBM material, then the installation of lining proceeds via assigning the material of lining to the corresponding shell elements [11].

\section{Results And Discussion}

The modeling of the tunnel building by using (TBM) is present a summary of the construction stages that is including the excavation of soil and installation of the lining concrete segment. The results obtained from the stresses of soil tunnel using the finite element method by failure criteria of the soil is MC model. Since Figures 3 and Figure 4 show the stress - depth curves of vertical and horizontal stresses of the native soil. For three vertical section are suggested which shown the influence of the stress-depth curve at the upper part and under part of the tunnel location. Total and effective vertical stresses are almost nearly linear with depth. This indicates constant of a unit weight. Also, it can be observed at depth $(15 \mathrm{~m})$ deviation of total and effective horizontal stresses due to the variation in the soil layers (from clay to sand) 


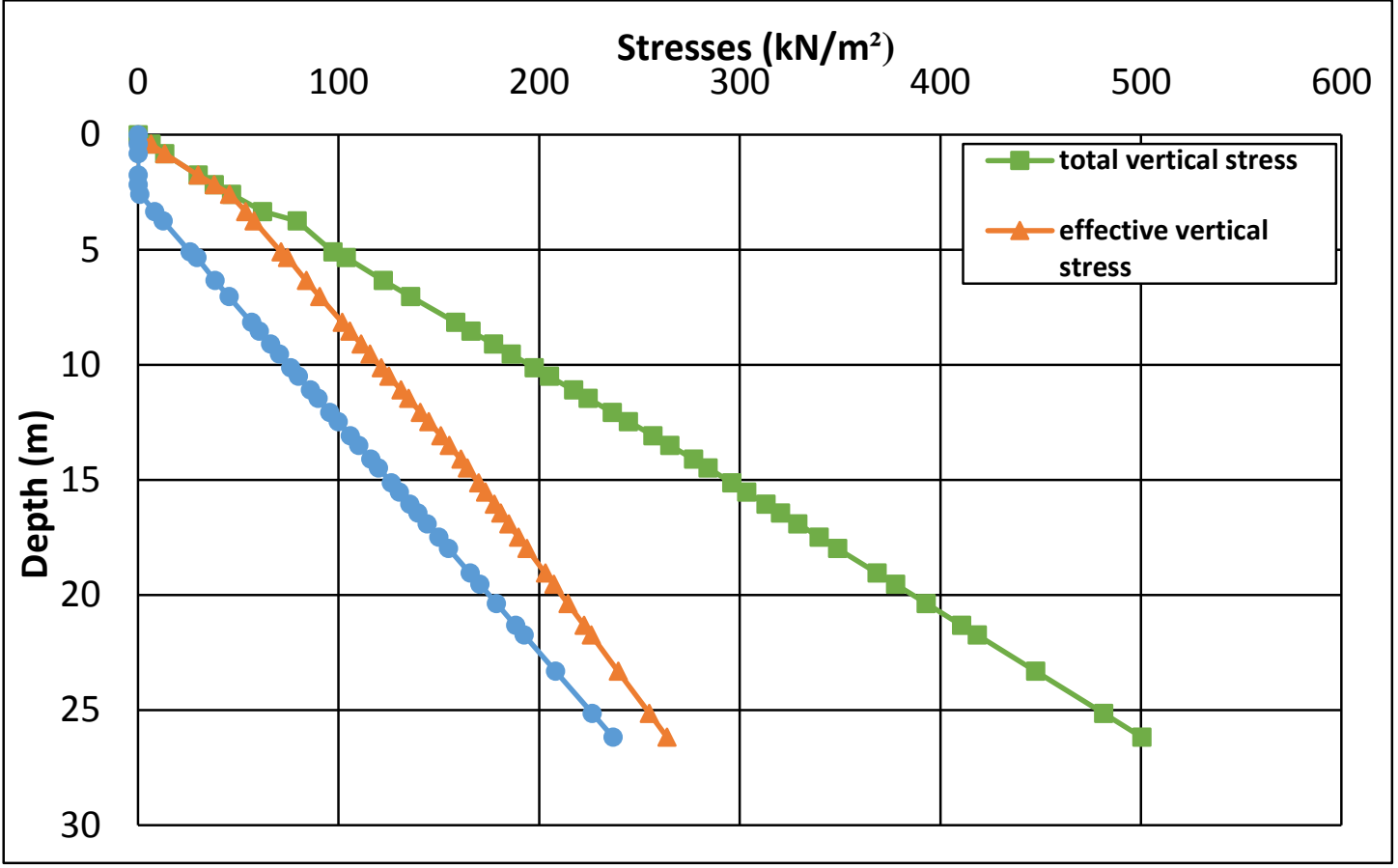

Figure3: Distribution of the vertical stresses of native soil.

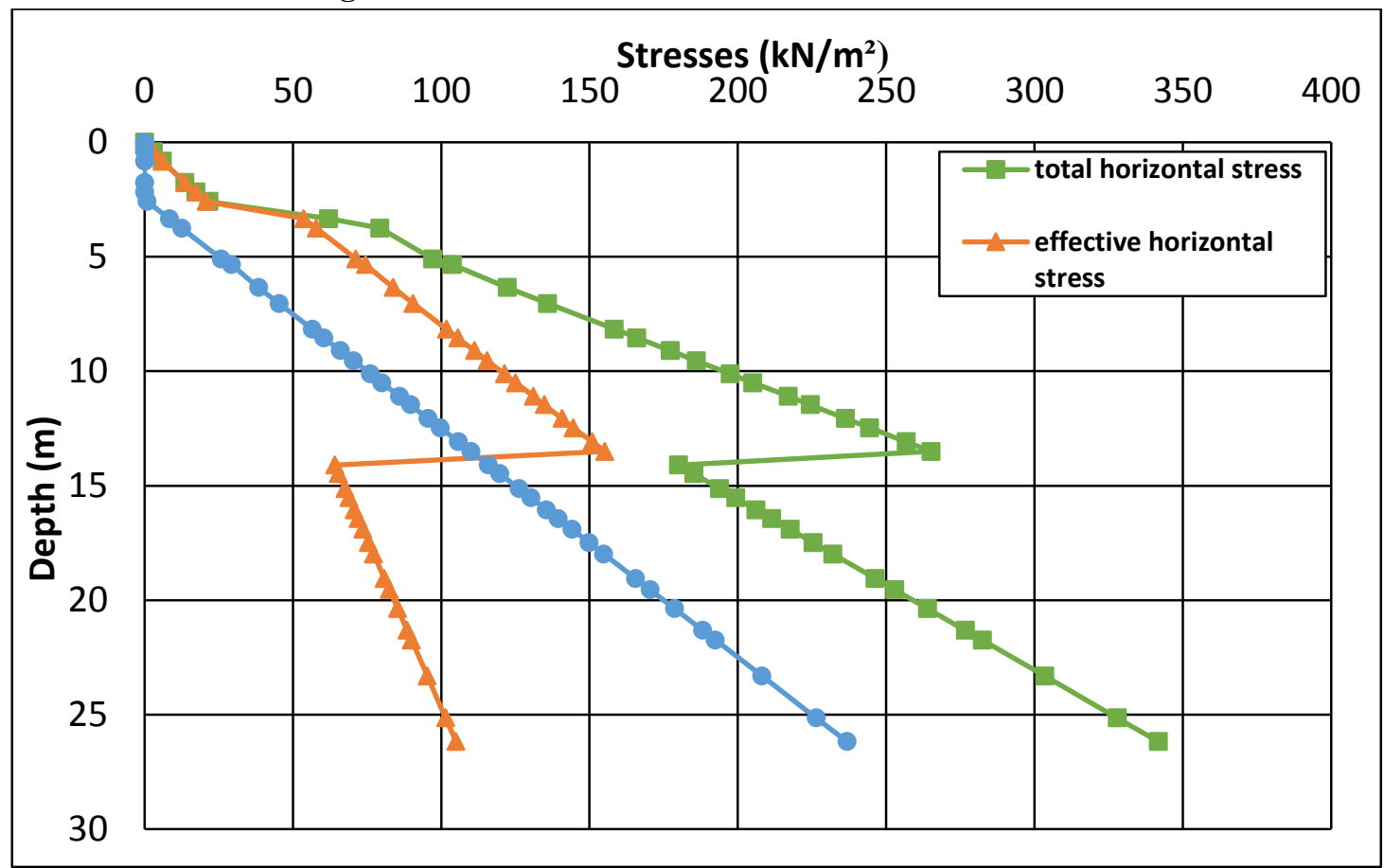

Figure 4: Distribution of the horizontal stresses of native soil.

\section{The stresses surrounding tunnel zone}

\section{i. The First section}

This zone represents the data through tunnel or very close center line of tunnel $(x=0$ with variations at $x-$ direction $=26.5 \mathrm{~m}$, and different depths $\mathrm{z}$ ), Figure $5 \mathrm{a}$ and $\mathrm{b}$ ) is explained the total vertical and horizontal stresses during construction of tunnel. In general, the behavior of total stresses can be seen clear which is same behavior for all phases with a slight difference between first phase, second phase and other phases due to the first phase is beginning tunnel excavation of TBM. Also it can be shown the all the phases is identical with native soil except the first phase. 


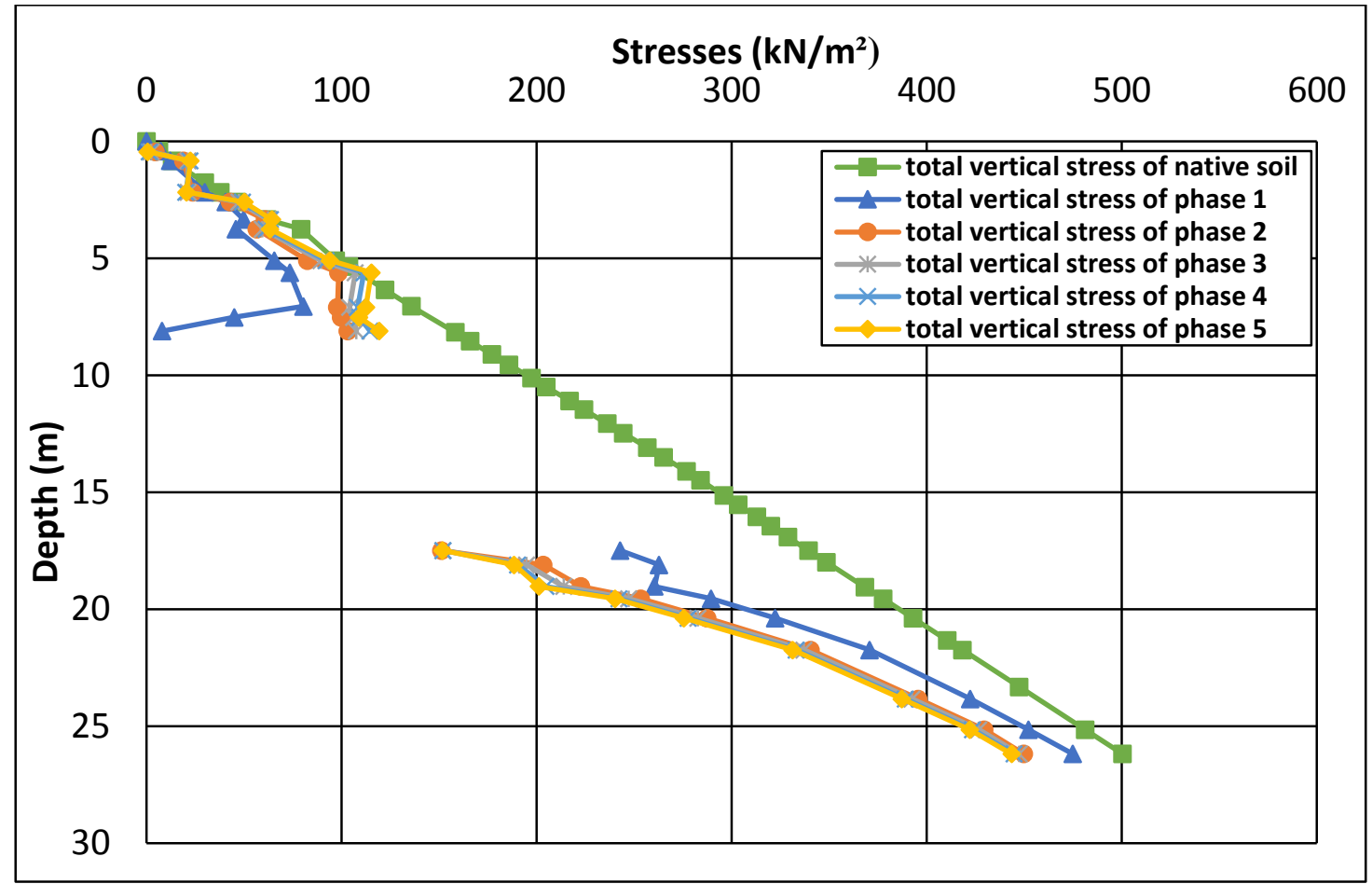

(a)

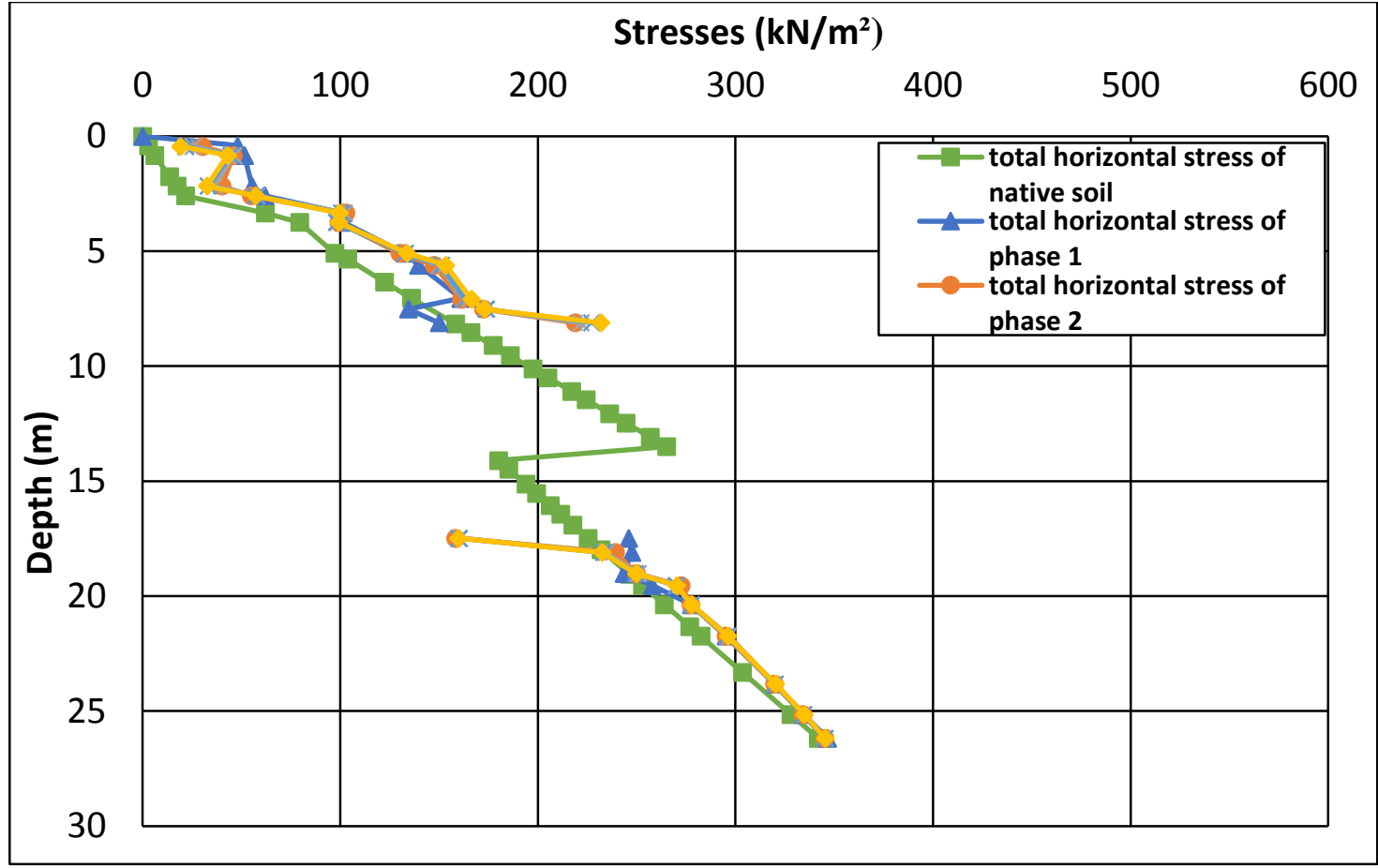

(b)

Figur 5: Distribution stresses during construction of tunnel at $x=0$ (a) vertical stress, (b) horizontal stress

\section{i. The Second Zone}

This distance represents the data inside tunnel zone at $\mathrm{x}=5$ with deviations from the tunnel centerline to show the distributions of stresses curves through stages of construction of the tunnel, the Figure (6a, and b) show that vertical and horizontal total stresses. It is worth mentioning stress- depth curves, in this case, at $\mathrm{x}$ direction $=5$ is very close to the tunnel edges which is far by 1 or $2 \mathrm{~m}$ from center line of tunnel, while the edge of a diameter of the tunnel expires at $\mathrm{x}=4.25 \mathrm{~m}$. The behavior of total vertical stress can be shown clearly which is same behavior for all phases with a very slight difference between first phase, second phase and other phases due to the first phase is beginning tunnel excavation of TBM, as shown in Figure 6a. While horizontal total and effective stresses are depended on soil properties (laterally 
coefficient K) and the influences of the tunnel boring machine vibrations during construction with a slight difference between the first phase and other phases due to drilling but in general behavior for the horizontal total and effective stress can be seen clearly which are identically behavior of all phases.

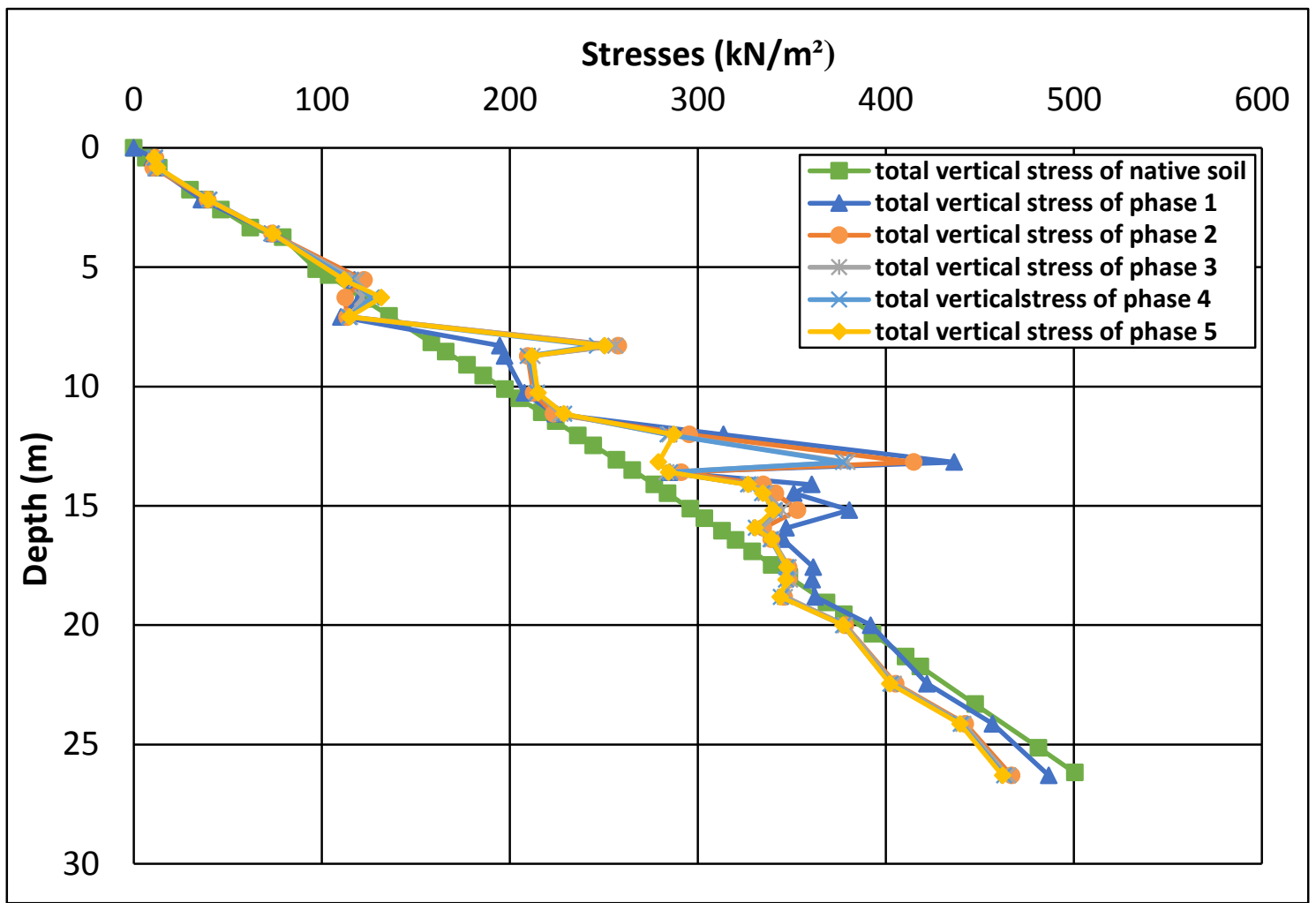

(a)

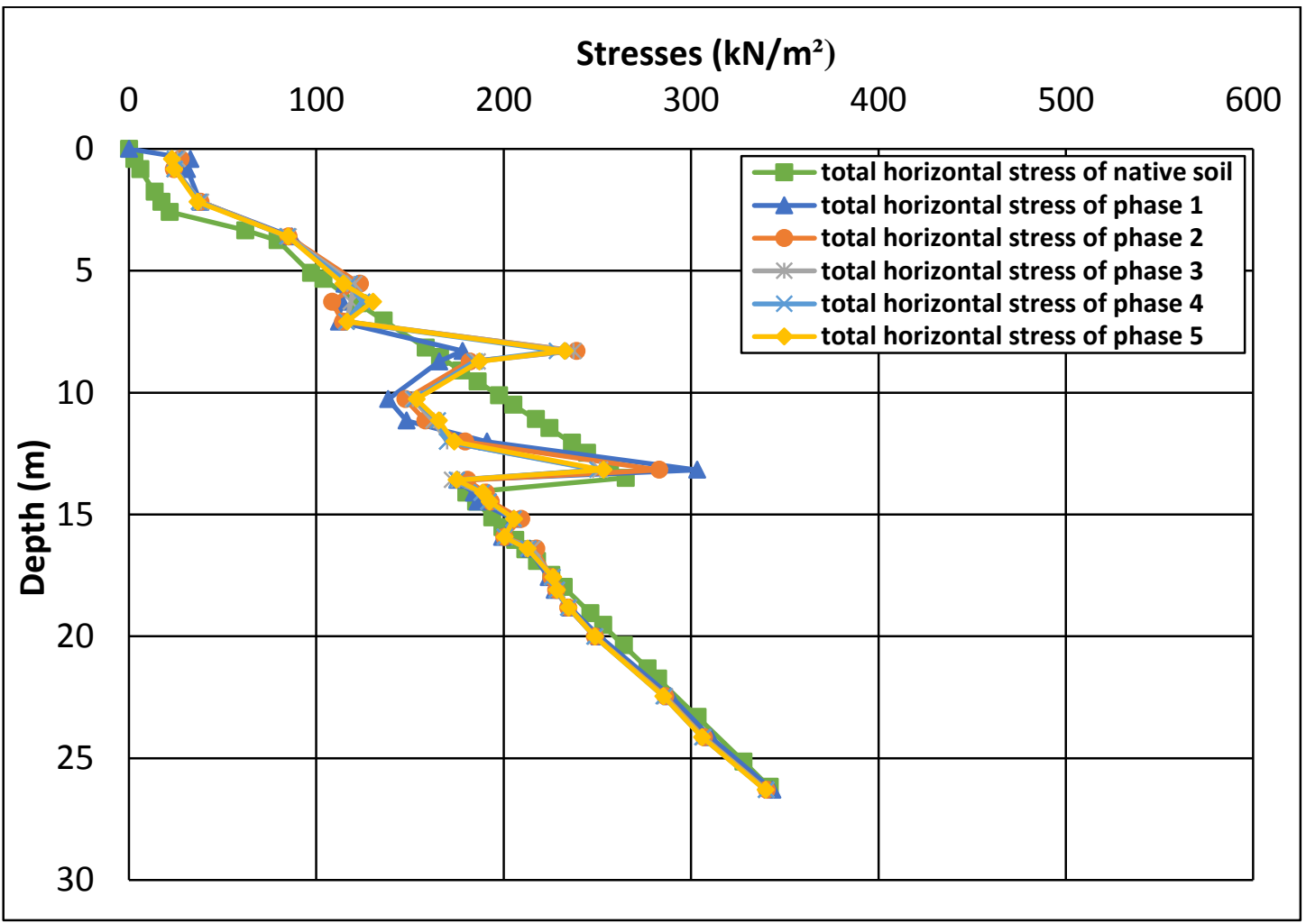

(b)

Figure 6: Distribution of total stress $x=5$ during construction of the tunnel in (a) vertical stresses, (b) horizontal stresses. 


\section{ii. The Third Zone}

This zone represents the data which is far from tunnel zone at $\mathrm{x}=8 \mathrm{~m}$ with deviations from the tunnel centerline. It is worth mentioning the stress- depth curves of this case, which is convergent to the native soil due to this zone is located far away from the excavation zone with slight deviations between phases of construction, as shown Figure $(7 \mathrm{a}$, and $\mathrm{b})$ is showing this vertical and horizontal total stresses. In general, the behavior of total vertical and horizontal stresses can be observed clearly to have same behavior for all phases with a very slight difference between first phase and other phases due to the first phase is beginning tunnel excavation of TBM but the deviations between phases of construction and native soil especially at middle part of the tunnel due to drilling area, as shown Figure $7 b$

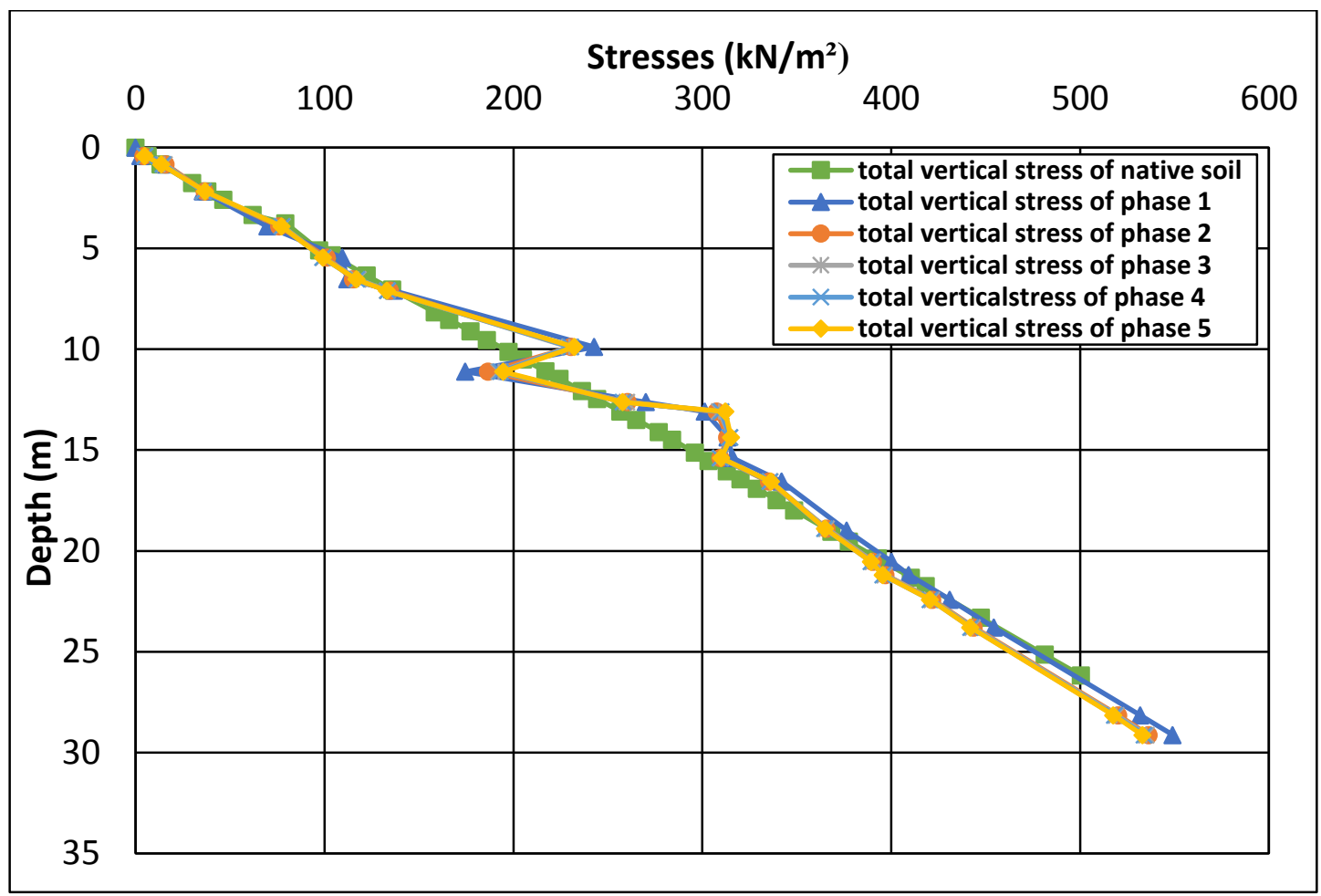

(a) 


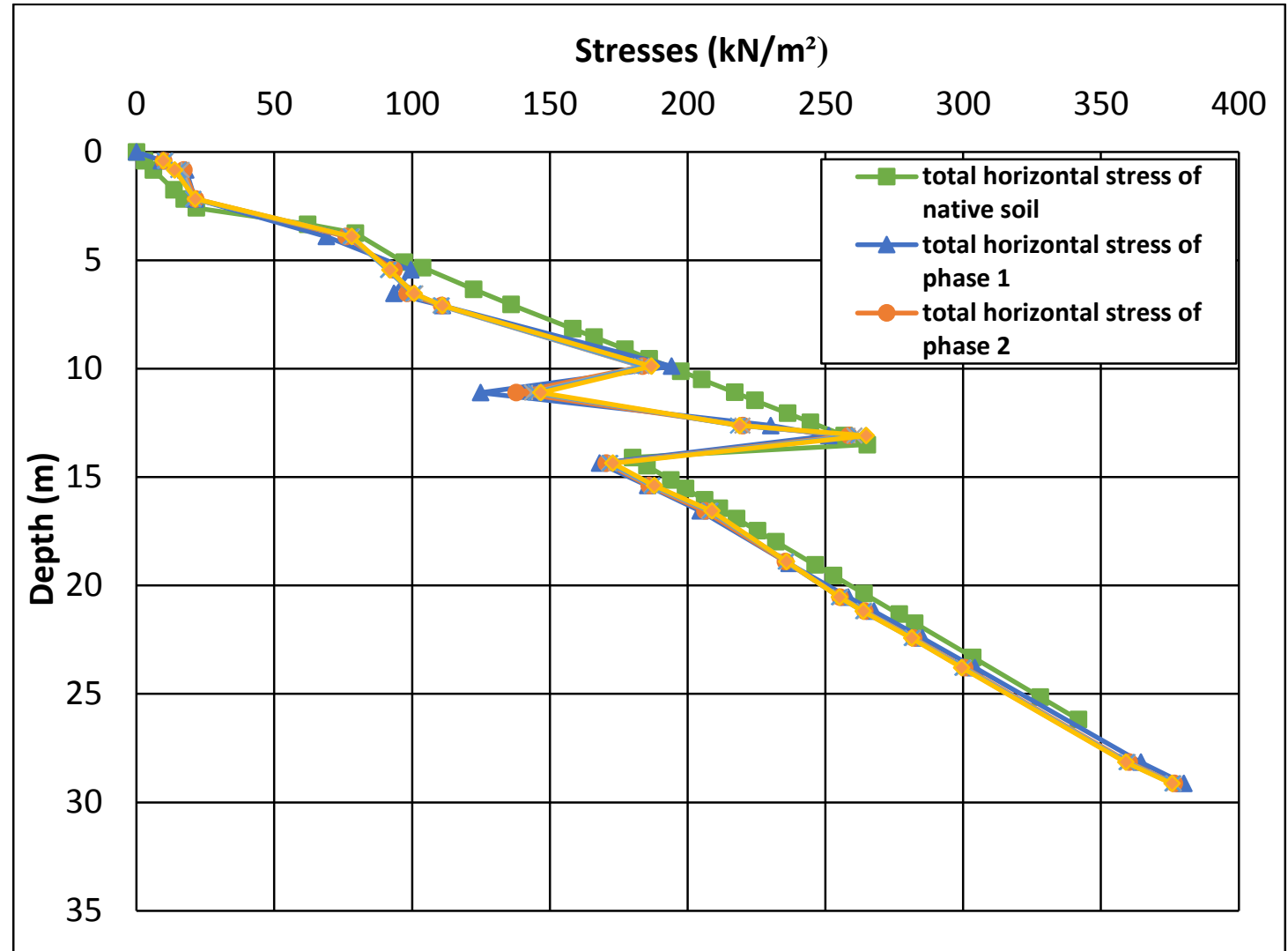

(b)

Figure 7: Distribution of total stress $x=8$ during construction of the tunnel in (a) vertical stresses, (b) horizontal stresses.

\subsection{Surface Settlement Surrounding the Tunnel Zone}

Ground movements around tunnels lead to surface subsidence. The estimation of surface settlements for each phase through construction stages and noting the value of a settlement when the drilling machine is advanced into the soil to a final phase of this tunnel model. Figure 8 shows surface settlement which is estimated by finite element method. Where this figure shows the surface settlement of all the phases as at the first phase which differs from the other phases since the surface settlement is the highest at this phase. While the other phases are convergent because these phases represent advance of TBM by value $1.5 \mathrm{~m}$ for each phase during construction of the tunnel. 


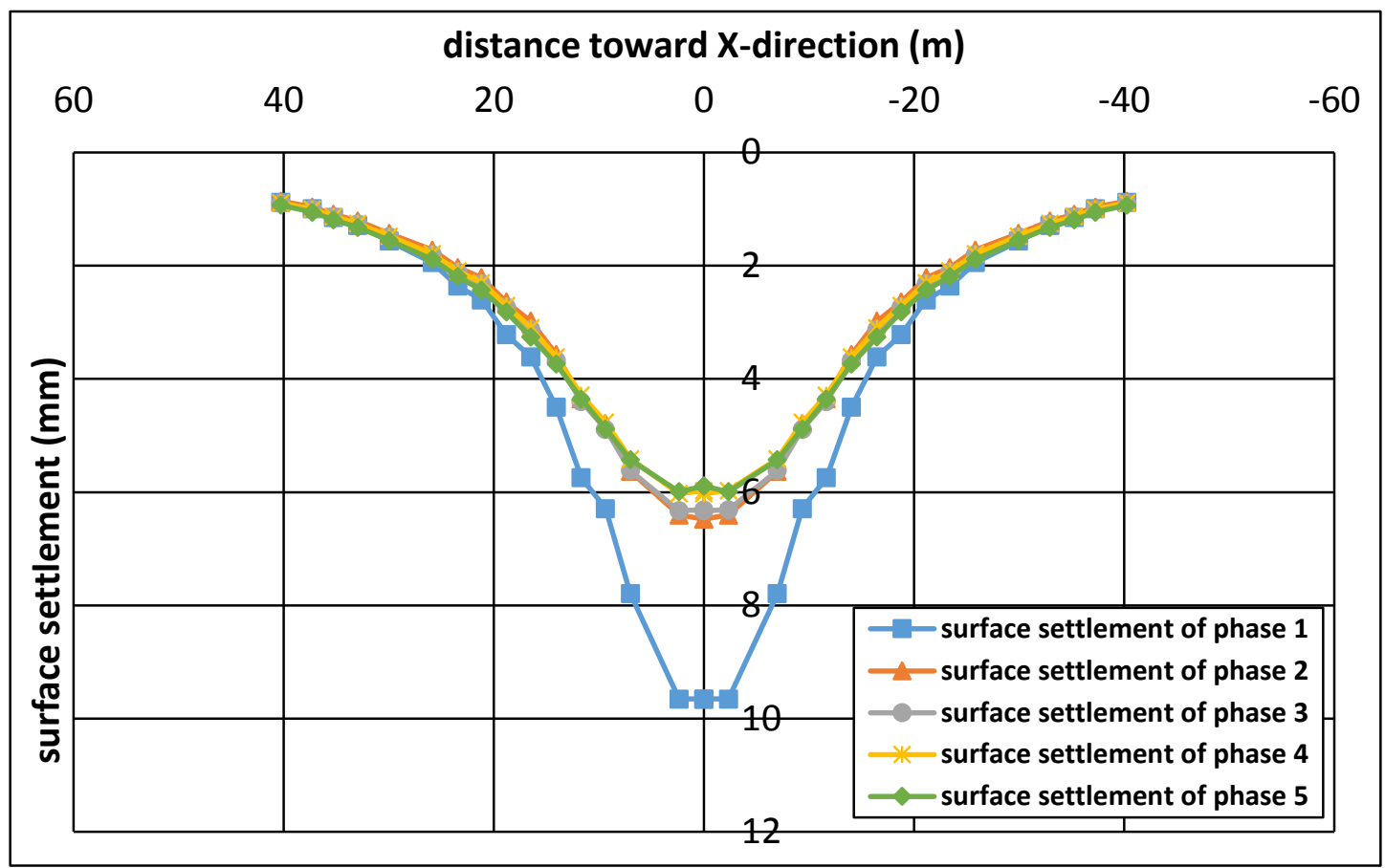

Figure 8: Surface settlement of all the phase and comparison during stages construction.

\section{Conclusions}

In general aspects, this study is carried out to emphasize the effect of tunneling work, namely the TBM, on the surrounding soil. As such, what is constructed before tunneling in soil or on soil is affected in different patterns according to the following factors believed by the author:

i. Type of soil profiles

ii. Type of the proposed structure

iii. Distance away from the TBM tunnel

A 3D finite element analysis which used to understand the performance of the tunnel construction system using a tunnel boring machine (TBM). The analysis of model takes into account the change in pressures of this mechanize, the non-linear behavior of the soil, and the construction advance during construction stages for $1.5 \mathrm{~m}$ of each stage. It is worth to mention that the maximum recorded displacement is $10 \mathrm{~mm}$ and is location in above of tunnel with $(\mathrm{x}=0)$. The surface settlement as shown in Figure 8, where imposes author problem to the shallow foundation. If a surface foundation is already constructed in the direct upper zone of TBM tunnel, then a differential settlement may arise in the structure above the tunnel. Lambe, 1979 offers table and charts for the admissible differential settlement and tilt considered. Form chart it is concluded that tilt will possibly occur and it depends on how tall is the upper structure is

\section{Acknowledgment:}

This work was supported by Diyala University, Civil Engineering Department, which is gratefully acknowledged Dimitrios, Kolymbas,Tunneling and Tunnel Mechanics a Rational Approach to Tunneling, 2005

\section{References}

[1] Obaid, A. K., Assessing the Behavior of Excavations by Finite Element Method, M.Sc. Thesis, University of Technology, Iraq,2001.

[2] Sharifzadeh, M., F. Kolivand, M. Ghorbani and S. Yasrobi,Design of sequential excavation method for large span urban tunnels in soft ground-Niayesh tunnel. Tunnelling and Underground Space Technology 35: 178188, 2013.

[3] Hassan O. Abbase, Evaluation of Sand Constitutive Models for Analysis of Piled Raft Foundation, Diyala Journal of Engineering Sciences, Vol.11,No.1/5,(2018)

[4] Jasim M. Abbas , Qasim A. Aljanabi , Zainab Ali Mutiny, Slope Stability Analysis Of An Earth Dam, Diyala Journal of Engineering Sciences, Vol.10,No.1 ,pp.106-117, (2017)

[5] Alireza Salimi ar, Mohammad Esmaeili and Bahram Salehi, Analysis of a TBM Tunneling Effect on Surface Subsidence; A case study from Iran. World Academy of Science, Engineering and Technology 78, 2013. 
[6] Shabna P S and Dr. N Sankar, Numerical Analysis of Shallow Tunnels in Soft Ground Using Plaxis2D. International Journal of Scientific \& Engineering Research, Volume 7, Issue 4, April-2016, 978-1-13800146-6. ISSN 2229-5518.

[7] Maji, V. B., and Abite Adugna. "Numerical modeling of tunneling induced ground deformation and its control." International Journal of Mining \& Geo-Engineering 50.2 (2016): 183-188

[8] Melazab. E. LEl-Kilany, Taha Ibrahim. A. EL-Sayed, and R. A. Mohab , Numerical Analysis of Tunnel Boring Machining Soft Ground. Jokull Journal, Vol 67, No.5; May 2017.

[9] Bowles, Foundation Analysis and Design, Fifth ed, 1996.

[10] Brinkgrever, R.B. J.Finite Element Code for Soil and Rock Analysis, User Manual Plaxis 3D The Nederland's, Delft University of Technology by Plaxis bv. Version 2013.

[11] T.William Lameb Robert V.Whitman, Soil Mechanics, fifth ed, (1979). 